\title{
Vestir desde la disidencia: resistencia y visibilidad desde la experiencia de tres activistas peruanxs
}

Dress and Dissent: Resistance and Visibility From the Experience of Three Peruvian Activists

Fabiola Bustamante es licenciada en Publicidad por la Pontificia Universidad Católica del Perú (PUCP) con estudios en Fashion Management y Comunicación de Moda (Universidad del Pacífico e instituto Polimoda de Florencia). Tiene entre sus líneas de investigación el arte textil como patrimonio cultural.

Raisa Ferrer es licenciada en Comunicación para el Desarrollo por la PUCP y magíster en Gestión Pública por la Universidad de Potsdam de Alemania. Su principal tema de interés radica en cómo las decisiones públicas y los discursos hegemónicos impactan la cotidianeidad de las personas. 



\section{Vestir desde la disidencia: resistencia y visibilidad desde la experiencia de tres activistas peruanxs \\ Dress and Dissent: Resistance and Visibility From the Experience of Three Peruvian Activists}

Fabiola Bustamante Almonte y Raisa Ferrer Pizarro

Pontificia Universidad Católica del Perú

fabiola.bustamante@pucp.pe / raisa.ferrer@pucp.pe

Recibido: 12-05-2019 / Aceptado: 16-10-2019

https://doi.org/10.1880o/conexion.201902.006

PALABRAS CLAVE / KEYWORDS

Comunicación, vestir, cuerpos no hegemónicos, activismo, identidad /

Communication, dressing, non-hegemonic bodies, activism, identity

\section{RESUMEN}

Este artículo exploratorio analiza cualitativamente trayectorias del vestir de personas que habitan cuerpos no hegemónicos y participan en espacios de activismo, y se pregunta por el rol del indumento en los procesos de comunicación. Para ello, se recogieron las perspectivas de tres activistas peruanxs, con el objetivo de conocer de primera fuente experiencias en las que la vestimenta se usa como herramienta para elevar activamente mensajes transgresores que reivindiquen sus identidades. Durante las conversaciones pudimos entender, además, cómo se configuran sus subjetividades en los márgenes de una socie- dad como la peruana, en la que la moda responde a reglas estrictas y «el buen vestir» se restringe especialmente en favor de cuerpos hegemónicos y géneros binarios.

\section{ABSTRACT}

This exploratory article analyzes in a qualitatively way clothing trajectories of people who inhabit non-hegemonic bodies and participate in spaces of feminist activism. A series of interviews were carried out with the objective of knowing first-hand experiences in which clothing is used as a tool to actively raise transgressive messages that claim their identities. During the interviews we could also understand how subjectivities are configured on the margins of a society like Peru, where getting dressed responds to tacit and strict rules and fashion is addressed to hegemonic bodies that also fit binarism. 
Vestir desde la disidencia: resistencia y visibilidad desde la experiencia de tres activistas peruanxs ${ }^{1}$

\section{Introducción}

Este texto exploratorio busca, de manera primaria, aportar a la identificación de aspectos relacionados con el vestir como lenguaje y acción comunicativa. De manera más específica, pretende contribuir al conocimiento de tendencias en torno a los procesos de resistencia en los que personas con identidades no hegemónicas que habitan cuerpos disidentes utilizan el vestir como medio de comunicación para emitir un mensaje sobre su identidad, e indagar en las respuestas o reacciones que reciben por esta acción comunicativa. En un primer momento, el artículo revisa brevemente los conceptos de moda, vestir y vestimenta como lenguaje, así como disidencia corporal y performatividad de género. Luego, describe las experiencias de vestir el cuerpo por parte de personas que se autoubican dentro de la disidencia. De igual manera, identifica aspectos de discriminación asociados a la vestimenta llevada por cuerpos no hegemónicos.

Este artículo contribuye a la reflexión que se sostiene desde los estudios de la comu- nicación sobre la indumentaria y la moda, cuya relevancia académica se extiende a la comprensión del vestir como un proceso comunicacional, pero también como un sistema de signos que corresponden a un lenguaje no verbal dentro de una sociedad, como detalla Umberto Eco (1976), quien explica que la semiología ha permitido ampliar el conocimiento del carácter comunicativo del vestido.

\section{Métodos}

El presente artículo es de carácter exploratorio, por tratarse de un tema académicamente poco investigado aún en nuestra región y contexto. Se trata de una primera aproximación a la temática del indumento como medio de comunicación desde la perspectiva de tres activistas que son, a su vez, miembros de una sociedad. Esta última es entendida, para fines de este artículo, desde una perspectiva socioconstruccionista, es decir, la sociedad como una realidad intersubjetiva construida mediante el intercambio de sentidos, en la que el conocimiento es incorporado como resultado de la interacción en la vida cotidiana (Berger y Luckmann, 1986).

El objetivo del artículo es aportar a la reflexión y comprensión de algunos de

\footnotetext{
${ }^{1}$ Las autoras de este artículo agradecen y valoran enormemente el tiempo, la apertura y las reflexiones de Gahela Tseneg, Santiago Balvín y Orlando Sosa, sin cuya contribución este artículo no hubiera sido posible. Gahela Tseneg (26 años) se identifica como «joven trans afroserrana»; estudió derecho y pertenece a la Federación Nacional de Mujeres Campesinas, Artesanas, Indígenas, Nativas y Asalariadas del Perú (Fenmucarinap). Santiago Balvín (29 años) se identifica como una persona «trans masculina y serrano huancaíno»; estudió arquitectura y pertenece al colectivo Diversidad Trans Masculina. Orlando Sosa (27 años) reivindica ser «afroperuano, marica y gordo»; estudió economía y trabaja como investigador en el sector de artes y como educador comunitario.
} 
los sentidos detrás del uso de la vestimenta, mas no aspira a la generalización de sus resultados ni es concluyente en estos. Como ejes de reflexión, parte de preguntas como las siguientes: ¿bajo qué concepto de «comunicación» es la vestimenta un medio para transmitir un mensaje?, ¿qué uso comunicativo podría tener la vestimenta en la cotidianeidad de personas activistas?, ¿a qué reacciones identificables puede llevar el uso de determinada vestimenta por cuerpos disidentes? Sin embargo, para comprender un mensaje, es necesario comprender a quien lo emite (Rizo García, 2009); por ello, la primera parte del artículo pretende describir el mundo subjetivo de tres activistas, enfocándose en las causas que defienden y en las identidades que reivindican.

Para el desarrollo de este artículo se usaron técnicas de investigación cualitativa, porque permiten abordar aspectos complejos e indagar a mayor profundidad en la cotidianeidad de las personas entrevistadas, en este caso específico, con un énfasis en los usos que dan a la vestimenta activistas que habitan cuerpos no hegemónicos. Así, se desarrollaron entrevistas semiestructuradas a profundidad a Orlando Sosa, Santiago Balvín y Gahela Tseneg. Duraron cerca de una hora y fueron grabadas con el consentimiento de las personas entrevistadas, y luego transcritas literalmente (ad verbatim). El presente artículo las cita con sus nombres reales, también con su consentimiento.
Durante la entrevista, se recogió información sobre la relación entre su uso del indumento y sus procesos personales de autoexploración identitaria, así como sobre sus experiencias de acceso al indumento y expresión identitaria en espacios públicos. Las entrevistas permitieron conocer las perspectivas de lxs activistas sobre su forma de vestir antes y después del activismo, la importancia del vestir en el proceso de reivindicación de la identidad, sus opiniones sobre la industria de la moda y su intención comunicativa al vestir. Posteriormente, se elaboró un libro de códigos a partir de las respuestas obtenidas en las entrevistas, y los datos fueron codificados y analizados cualitativamente para encontrar patrones comunes con el fin de seguir explorando en investigaciones futuras con una muestra mayor. Finalmente, para el análisis de los datos recogidos, nos apoyamos en dos campos teóricos: los estudios de género y performatividad, y los estudios de moda y comunicación, entendida esta última como negociación de significados.

Cabe señalar que este artículo aborda la relación entre el cuerpo y el indumento como medio de comunicación. Este es un campo de estudio aún subexplorado, en tanto que el indumento es usualmente abordado como «objeto» situado en un momento histórico, mas no en relación con quien lo lleva, ni mucho menos como medio para transmitir un mensaje. Esto sigue la línea de trabajo propuesta por 
Joanne Entwistle, en la cual el vestir se ve como práctica corporal y actividad inserta en las relaciones sociales (Entwistle, 2002).

\section{Marco teórico}

\subsection{El vestir y la moda}

Etimológicamente, vestir, proviene del latín vestīre, que significa 'ropa'. Como verbo, su acepción principal remite a la acción de cubrirse el cuerpo con prendas; sin embargo, el Diccionario de la lengua española también señala esta otra acepción: «Disfrazar o disimular artificiosamente la realidad de algo añadiéndole adornos» (Real Academia Española y Asociación de Academias de la Lengua Española, 2014, definiciones 1 y 5). Ello nos lleva a la siguiente interrogante: ¿para qué y por qué cubrimos e, incluso, disfrazamos nuestros cuerpos?

Según Flügel, «la vestimenta sirve para cubrir el cuerpo y gratificar así el impulso de pudor. Pero al mismo tiempo puede realzar su belleza, y esta fue probablemente su función más primitiva» (2015, p. 13). Y apunta también este autor:

Por medio del vestido tratamos de satisfacer dos tendencias contradictorias y, por lo tanto, tendemos a considerarlo desde dos puntos de vista incompatibles: por un lado, como un medio para desplegar nues- un recurso para ocultar nuestra vergüenza (2015, p.12).

En la misma línea, para Andrea Saltzman (2004), el vestido cubre y descubre al cuerpo, insinúa, acentúa, oculta sus formas y crea una nueva piel que se relaciona con el cuerpo de manera constante.

Por otro lado, Isabel Cruz de Amenábar señala que, desde la época primitiva, la vestimenta ha tenido más fines que solo cubrir el cuerpo:

Decoración, pudor y protección, en este orden serían las motivaciones profundas que han inducido a la humanidad a dedicar tantos empeños, recursos e intereses al vestido.

La antigua sentencia «El hábito no hace al monje», indicativa de la consideración del ser humano más allá de su apariencia vestida, se invierte hoy para ciertos estudiosos, quienes subrayan la importancia de la imagen externa del hombre, reveladora del sujeto como ser individual y como ente social (1986, pp. 178-179).

A diferencia del vestir, que resulta una práctica inherente a la vida social en todo el mundo, la moda es una construcción social que aparece mucho después y en Occidente. Para Gilles Lipovetsky,

la moda no se produce en todas las épocas ni en todas las civilizaciones. 
[...] En contra de la idea de que la moda es un fenómeno consustancial a la vida humano-social, se la afirma como un proceso excepcional, inseparable del nacimiento y desarrollo del mundo moderno occidental. Durante decenas de milenios la vida colectiva se desarrolló sin culto a las fantasías y las novedades, sin la inestabilidad y la temporalidad efímera de la moda, lo que no quiere decir sin cambio ni curiosidad o gusto por las realidades de lo externo (1996, p. 23).

La moda es anexa al vestir; ha sido y sigue siendo tratada en el diálogo habitual como un tema superficial y accesorio debido, probablemente, a su esencia fugaz y mudable. No obstante, como indica Cruz de Amenábar,

la moda - el estilo en el vestir - no es solamente un fenómeno fútil y frívolo; es también un signo del dinamismo de aquellas sociedades en ruptura con la tradición, que se preocupan tanto de cambiar los colores, los materiales y las formas del traje, así como de alterar el orden de las categorías sociales y el mapa del mundo. Hay que preguntarse entonces: ¿será tal vez necesaria para abrir las puertas a la innovación, al progreso, una cierta inquietud, un afán de cambios, que se traduce hasta en los vestidos, en el calzado y en la manera de peinarse? (1986, p. 177).
En ese sentido, con esta investigación quisimos también explorar si este ánimo de innovación y cambio muy propio de la moda comulgaba de alguna manera con la disidencia de las personas entrevistadas.

\subsection{Vestimenta, lenguaje $y$ comunicación}

La discusión sobre el uso de indumento sugiere que toda forma de vestirse y adornarse, sea tradicional o moderna, tiene su raíz en la necesidad humana de comunicarse a través de símbolos. Si bien la ropa y otro tipo de adornos pueden usarse con fines de protección, estos son parte de la cultura expresiva de una comunidad. La ropa tiene una relación con la identidad, y les dice a otros algo sobre el género, clase $u$ origen de quien lleva la prenda (Entwistle, 2000).

Para Entwistle (2000), vestirse en la cotidianeidad es una negociación entre el sistema de moda y sus estructuras, las condiciones sociales - género, clase, etcétera-y las normas sociales. Tiene el indumento, además, una clara función social: «El acto individual y muy personal de vestirse es un acto de preparar el cuerpo para el mundo social, hacerlo apropiado, aceptable, de hecho, hasta respetable y posiblemente incluso deseable» (Entwistle, 2002, p. 12). Asimismo, la autora explica que esta práctica involucra diferentes niveles de conciencia en términos de cómo presentamos nuestro cuerpo en público y en la intimidad. En los casos en los que una persona 
decide no cumplir con los códigos de vestimenta, es consciente de que podría ser leída como rebelde. Sin embargo, ¿podría ser la vestimenta un medio para declarar un mensaje? ¿Tiene el vestir un lenguaje potente para fines insurgentes?

Para Twigg (2009), la ropa es un artefacto cultural, cuyos significados son ambiguos, sujetos a la interpretación e incertidumbre. Entwistle (2014), analizando los postulados de Fred Davis, señala que la ropa es significativa, pero ambigua e imprecisa; su poder real viene de su habilidad para sugerir, evocar o resistir un significado fijo, y explica que, si bien sí es un tipo de código y lleva mensaje, estos no son tan claros como una oración hablada o escrita. Sin embargo, más allá de lo ambivalentes que puedan ser la ropa y lo que se desea comunicar con ella, Entwistle (2014, párr. 4) resalta que «en la vida cotidiana la ropa es la insignia con la cual nos leen y leemos a otras personas» ${ }^{2}$.

Patrizia Calefato (2002) va más allá y sostiene que el vestido es una forma de lenguaje no verbal y que, como tal, asume sentido a través de un sistema de principios, así como la sintaxis en la gramática:

Como lenguaje, entendido en este sentido, el vestir funciona según una especie de «sintaxis», es decir, según un sistema de reglas más o menos constantes según se trate, por ejemplo, de atuendo tradicional o traje a la moda. Estas reglas permiten al traje y al revestimiento del cuerpo en general asumir un sentido, ya sea aquel expresable como un verdadero significado social codificado en el tiempo y en el traje, o bien como la pura y simple exhibición de signos sobre el cuerpo en conexión entre ellos, según los criterios de asociación establecidos por el sistema de la moda (Calefato, 2002, p. 13).

$\mathrm{Si}$ el vestir puede ser reconocido como un lenguaje, esto significa que con él se pueden llevar a cabo procesos de comunicación. Barnard (2002) hace hincapié en lo señalado por J. Fiske en Introduction to Communication Studies (1990) sobre dos principales escuelas del estudio de la comunicación: mientras que ambas brindan una definición general de la comunicación como una interacción social a través de mensajes ${ }^{3}$, cada una entiende la definición de manera sutilmente distinta. Fiske llama a la primera de estas escuelas como la escuela del proceso, entendiendo la comunicación como un proceso en el cual alguien dice algo a otro a través de un medio, lo que genera algún tipo de reacción. Así, una prenda de vestir podría configurarse como un medio. La intención del emisor es tan importante que se convierte en el mensaje en sí mismo; sin ella, sin el mensaje, la comunicación no se podría llevar a cabo. La eficiencia del proceso de transmisión también es 
relevante porque, si llega de una manera distorsionada, puede significar que el proceso de comunicación está fallando de alguna manera. Finalmente, es importante el efecto que el mensaje produce en quien lo recibe, porque es allí donde se genera la interacción. Barnard se pregunta entonces quién es el emisor del mensaje. Si bien es cierto que la respuesta obvia sería que es quien usa la prenda, habría que considerar también que detrás del diseño de esa prenda hubo una intención, la del diseñador. Asimismo, habría que preguntarse también qué sucede cuando estas prendas son modificadas para cambiar la intención que se quería generar a través de ellas desde su creación.

Barnard continúa definiendo el segundo modelo de comunicación a través de Fiske, quien lo llama modelo semiótico o estructuralista, y menciona que la semiótica define la interacción social como aquella que constituye al individuo como miembro de una cultura o sociedad particular y, ya que la comunicación se entiende como interacción social a través de mensajes, se concluye que esta tiene la capacidad de hacer que un individuo sea miembro de un grupo. Más que un miembro de un grupo comunicándose con los miembros de otro grupo, como en el primer modelo, en un inicio es la comunicación entre individuos la que los hace miembros de un grupo sociocultural. Esta estructura de significados culturales les permite construir una identidad por medio de la comunicación. En pocas pala- bras, la producción del sentido se genera a partir de una negociación entre emisores y receptores. Para Barnard este modelo es plausible al momento de hablar de moda y comunicación, pues es la interacción social a través de la ropa lo que genera que un individuo se haga un lugar en un grupo y no viceversa (Barnard, 2002, pp. 31-32).

\subsection{Cuerpos no hegemónicos y vestimenta}

Aunque la vestimenta provee caminos para resistir la hegemonía y abre posibilidades para la libertad expresiva y para comunicar identidad - cuando nos vestimos, llevamos con nosotros significados asociados a la clase, etnia, género y sexualidad-, puede, a la vez, ser fuente de represión y herramienta disciplinaria, como explican Tarrant y Jolles (2012). Los cuerpos son vestidos, adornados y maquillados siguiendo pautas culturalmente establecidas (Kogan, 1993). El manejo de la apariencia es además para Cahill (1989) el principal mecanismo por el cual se sigue reproduciendo intergeneracionalmente el género sobre la base del sexo, y para Rudd y Lennon (2000) la selección de prendas es una forma de practicar el manejo de la apariencia, al igual que lo puede ser hacer dieta, ejercitarse o pasar por procesos de cirugía. Durante la selección de las prendas, puede haber una intención expresiva, pero también una de camuflaje de la forma y tamaño del cuerpo (Rudd y Lennon, 2000). 
Por ello, también consideramos importante la revisión de conceptos como disidencia corporal y performatividad de género, dado que, a lo largo de este artículo, se reflexiona sobre la apropiación del indumento por parte de cuerpos gordos, trans y homosexuales.

Para Butler el género es una estrategia de supervivencia dentro de sistemas obligatorios, y los actos de género son corporales, y comprenden gestos, movimientos, posturas y comportamientos (Butler, 1988). A la vez, el género no es un hecho, sino una performance (desempeño) que se da de manera «ritualizada» (reiterada) en un contexto de restricción y que tiene consecuencias punitivas, dada la existencia de normas que regulan la diversidad de seres corporales. Para la autora ser «discretos» en nuestros actos nos humaniza ante la sociedad, y aquellos que fallan en actuar su género de maneras consideradas socialmente correctas son leídos como abyectos y empujados hacia la precariedad (Butler, 1990, 2002).

En una línea similar, para Entwistle (2002) el vestir se relaciona con el orden microsocial. La autora explica que las convenciones del vestir apuntan a que la carne (el cuerpo) sea inteligible y significativa para una cultura, y que, por ello, «un cuerpo que no encaja, que transgrede dichos códigos culturales» puede provocar «escándalo e indignación» (p. 14).
A partir de una lectura del análisis de Irving Goffman sobre el cuerpo y las interacciones, Entwistle entiende a la vestimenta como una práctica corporal situada y como un fenómeno intersubjetivo y social, que funciona como vínculo entre la identidad individual y la pertenencia social (Entwistle, 2014). La autora detalla cómo incluso las situaciones más informales tienen códigos de vestimenta que imponen, a través de normas sociales y códigos morales, formas de vestir los cuerpos. Asimismo, describe cómo «a menudo se habla de ropa en términos morales, usando palabras como "impecable", "bueno", "correcto" ${ }^{4}$ (Entwistle, 2014, párr. 5). En ese sentido, reflexiona sobre la «ropa apropiada» (Entwistle, 2000) y explica que los cuerpos que «no se ajustan o se burlan de las convenciones de su cultura y además no llevan puesta ropa considerada apropiada son considerados subversivos, y se arriesgan a la exclusión, desprecio o ridiculización ${ }^{5}$ (Entwistle, 2014, párr. 1).

Este artículo denomina cuerpos no hegemónicos a aquellos cuerpos que son leídos como lejanos de patrones normativos de género o de los ideales estéticos corporales o étnico-raciales construidos por la sociedad. La literatura también denomina a estos cuerpos como cuerpos desviados (deviant bodies) o cuerpos divergentes (divergent bodies). Murray 
(2007) señala que las personas internalizamos declaraciones sobre qué cuerpos son patológicos y cuáles normativos, y creemos que podemos llegar a conocer la esencia de una persona a través de la forma de su cuerpo; es decir, este "conocimiento» que no se cuestiona afecta cómo interpretamos la realidad y las interacciones que tenemos.

Andrea Ostrov (2015) comenta que todos los cuerpos ocupan un lugar, pero que existe un sistema de clasificación de cuerpos que, por el contrario, define cuáles son considerados fuera de lugar y, por ende, excluidos y hasta prohibidos. Para Klepp y Risst (2016), considerando los ideales corporales presentes en la sociedad y el mercado de moda, es posible argumentar que la mayoría de gente posee un cuerpo desviado $o^{6}$. Sin embargo, siendo más específica, Laura Contrera (2017) expone la existencia de «una policía de los cuerpos» que frena la diversidad, imponiéndole según la época estándares de salud, belleza y normalidad corporal, y explica que las personas con alto peso corporal y las intersecciones de los distintos ejes de dominación/opresión sufren experiencias de discriminación y fobia. En ese sentido, Flavia Costa (2008) alude al «dispositivo de fitness», partiendo del concepto de dispositivo de sexualidad desarrollado por Foucault, que reúne las exigencias de un cuerpo «correcto».

\section{Hallazgos}

\subsection{Sobre el contexto de las personas entrevistadas}

Las personas entrevistadas para esta investigación habitan cuerpos e identidades diversas, y se mantienen en el activismo actualmente. Para comprender los mensajes que comparten, es necesario conocerlas como emisores de mensajes y prestar atención a sus subjetividades (Rizo García, 2009). Por ello, a continuación, pasaremos a detallar cómo se autoperciben.

Orlando Sosa. Orlando tiene 27 años y es activista desde los 19. Desde hace cinco años ejerce una ética feminista en su estilo de vida. Considera un privilegio académico poder haberse acercado a los activismos a través de la investigación y en consecuencia explorar sus identidades desde ahí, pues expresa que muchos debates identitarios aún se mueven en torno a problemáticas esencialistas. De esta manera, asume el activismo desde una lógica interseccional y se reivindica como una persona gorda, racializada -al ser afroperuano-, y se identifica como «marica».

Santiago Balvín. Santiago tiene 29 años, es trans masculino y se identifica como serrano huancaíno y transfeminista. Está involucrado en el activismo desde el 2014. Cuando vivía con sus padres, solía ves- 
tir de manera más próxima a las normas sociales; luego de independizarse, decidió romper con las reglas que asocian el vestir a un género determinado. Antes del activismo, e incluso antes de reconocerse como una persona trans, solía apartarse de una expresión de género femenina. Considera importante cuestionar cómo los medios de comunicación moldean los estándares de cómo uno debe verse para encajar en la sociedad.

Gahela Tseneg. Gahela es una mujer trans y se describe como «afroserrana, feminista, socialista, malcriada y respondona». Señala que nació y creció «en una zona rural del interior del país», donde se desarrolló tratando de ocultar su identidad; en la universidad, dejó de reprimir quién era gracias a la interacción con jóvenes de la comunidad LGTBI y otras ramas del activismo, como el animalismo y el ambientalismo. Fue en un evento de voluntariado donde pudo conocer la experiencia de otras personas jóvenes activistas y reconocer que había una variedad de temas en agenda. Considera que esta visión le permite luchar con alegría en una sociedad que suele reprimir y restringir las identidades no hegemónicas.

\subsection{El rol de la dimensión relacional de la comunicación en las trayectorias de vestimenta}

Tarrant y Jolles (2012) explican que la vestimenta es una herramienta de agencia través de las conversaciones con Orlando, Santiago y Gahela, se puede evidenciar que sus prácticas de vestimenta antes de vincularse con el activismo o de empezar su proceso de autoconocimiento e identificación incluían cubrir partes del cuerpo para quitarles importancia ante el resto, e implicaban una disputa entre rechazar prácticas de vestimenta hegemónicamente relacionadas con el sexo que les fue asignado al nacer o, por el contrario, conquistar la identidad a través del cumplimiento de expectativas de la sociedad sobre la forma «correcta» de vestirse.

Por un lado, Orlando manifiesta que durante esa época la ropa fungía como «un instrumento que ayudaba a cubrir aquello de lo cual me sentía avergonzado». En cambio, Santiago señala que prefería usar ropa holgada porque, incluso antes de reconocerse como persona trans, deseaba apartarse de una expresión de género femenina: «Me gustaba usar cosas neutras porque para mí lo femenino era mostrar mucho cuerpo, usar ropa pegada que marcaba mi cuerpo, y eso me hacía ser leída como mujer». Gahela explica que en su caso, cuando empezó a usar la indumentaria que la sociedad atribuye a las mujeres, trató de «replicar lo que esta sociedad espera de una mujer. Una mujer sumisa y callada, que pacte con el patriarcado. Lo que hice fue ponerme dos kilos de maquillaje en la cara. Usar los tacos más altos que encontré». Se puede constatar que, por entonces, vestirse no significaba un acto de placer para las 
personas entrevistadas. Gahela menciona al respecto: «Para mí era un suplicio ir a comprar ropa y ver todas las mañanas ¿qué me voy a poner ahora?».

Aunque lo primero que rescatan de la interacción social con otras personas activistas es sentirse presentes en sus discursos - «Ella se paraba delante del escenario y decía "yo soy una mujer trans y mis hermanas son estas" y yo me quedé admirada», recuerda Gahela-, las personas entrevistadas coinciden también en que sus llegadas al activismo tuvieron relación con un cuestionamiento de su uso del indumento. En el caso de Santiago, manifiesta que conocer «la lucha de otras personas trans y cómo estas leían lo femenino y lo masculino, cómo mostrarse» lo ayudó a poder repensarse o cuestionarse. De igual manera, por su trayectoria de activista, Orlando ha podido conocer «chicos supermaricas, gordos, peludos y superfemeninos» que, en sus palabras, lo «han inspirado un montón».

Más específicamente, dentro de los espacios de activismo, Gahela, Santiago y Orlando también coinciden en que educarse sobre feminismo les permitió explorar las diversas identidades que han generado discriminación sobre su cuerpo, lo cual significó un primer paso para poder luego reflexionar sobre su vestir:

Yo tuve la suerte que, a la par que empezaba mi proceso de transición, conocí el feminismo. Porque yo recuerdo que al comienzo lo que hice fue tratar de replicar lo que esta sociedad espera de una mujer. Fue el feminismo que me llevó a cuestionarme y preguntarme qué tipo de mujer quiero ser (Gahela).

Las personas entrevistadas coinciden en que el proceso de vestirse va de la mano con un proceso de reconciliación con el propio cuerpo, lo cual se traduce en un mayor ejercicio de libertad al seleccionar y combinar prendas, así como en una reducción de la autocensura:

Últimamente uso colores más encendidos, aunque recibo críticas del entorno porque los colores así no «disimulan» mi figura (Orlando).

Puedo usar un top y prendas sugerentes, y puedo también taparme, pero eso va ser parte de mi decisión, porque yo lo quiera, no porque sea preferencia de alguien (Gahela).

Durante sus trayectorias activistas, la reconciliación con el propio cuerpo y la subsiguiente sensación de libertad expresiva a través del indumento se mencionan como fuertemente influidas por las interacciones sociales y cotidianas con otras personas con las cuales se sentían identificadxs. En este proceso, la comunicación aparece como actividad humana relacional, que implica la existencia de un ambiente comunicativo y la puesta 
en común de sentidos para generar comprensión (Rizo García, 2009).

No obstante, las tres personas entrevistadas suelen sentirse contrariadas al momento de buscar indumentos que satisfagan sus gustos y necesidades. La experiencia acostumbra ser distinta e incluso desagradable en comparación con aquellos cuyos cuerpos cumplen con el estándar reconocido como hegemónico en la sociedad y los medios de comunicación. Basta con revisar las revistas de moda, los comerciales de televisión o los escaparates de las tiendas por departamento para ver evidenciado un discurso acartonado en relación con el cuerpo, que no incluye dentro de lo «normal» a aquellos que escapen de ese modelo.

Este incuestionable divorcio entre la oferta de prendas de moda y la demanda de indumentos que puedan adaptarse a estos cuerpos se ve constatado en el trato de los trabajadores de aquellos espacios comerciales, quienes, a través de gestos o palabras de prejuicio, generan malestar en los compradores cuyos cuerpos se observan distintos. En las tres entrevistas, se mencionaron experiencias incómodas relacionadas con la interacción con los vendedores de ropa.

Así, la disidencia de sus cuerpos limita drásticamente el acceso a la adquisición de prendas en nuestras personas entrevistadas. Orlando menciona: «En centros lla, o es ropa muy cisgénera». En el caso de Santiago, quien se identifica como trans masculino, busca prendas que se aparten de la expresión de género femenino; sin embargo, lo que encuentra en tiendas solo responde a indumentaria de corte puramente femenino o masculino. Esta última, por lo general, no ofrece tallas que puedan corresponder a la estructura natural de su cuerpo.

No obstante, dichas limitaciones no han disminuido el deseo de usar ropas que les permitan sentirse cómodos y expresar sus identidades. En el caso de Gahela, una solución ha sido el trueque o la compra de prendas de segunda mano. A estas piezas las modifica, acción que realizaba con las prendas varoniles que usaba antes de su transición, y las hace menos holgadas. En el caso de la indumentaria que usa en la actualidad, esta adquiere, a través de la personalización, diversos rasgos que complementan su estilo personal. Comenta, por ejemplo: «Yo no solamente uso ropa femenina: uso ropa indígena, uso trenzas, polleras, sombreros, porque me gusta, me encanta. Más allá de un tema político, hay un tema de legado, de poder preservar ciertas tradiciones». Busca, entonces, no solo reafirmar su identidad como mujer trans, sino reivindicar su herencia, adaptando piezas tradicionales a su tenida, creada también con prendas de la industria de la moda que han sido alteradas por ella para adaptarse a su cuerpo. 
En el caso de Orlando, cuyo mayor inconveniente es encontrar ropa de su talla que, además, posea un diseño de su agrado, resuelve las barreras de la oferta comprando telas que usa para mandar a confeccionar prendas con las que pueda sentirse cómodo.

Durante las entrevistas, se reveló también que otra solución a la reducida propuesta que se encuentra en el mercado local es la compra en tiendas en línea de países extranjeros, donde puede hallarse mayor variedad de tallas e, incluso, imágenes de modelos con cuerpos no hegemónicos.

Cabe resaltar que las personas entrevistadas no buscan adaptar sus cuerpos al estándar, sino reivindicarlos tal cual son. Con ese objetivo, toman acciones sobre las prendas y se convierten en confeccionistas y curadores del indumento para la ideal expresión y exploración de su ser. «Nuestro proceso de reconciliación corporal ha sido también de reconciliación con la ropa que usamos», señala Orlando.

\subsection{El indumento como medio de comunicación no verbal para hablar desde la subjetividad}

El indumento, entendido como el conjunto de prendas que se usan al vestir, cumple diversos usos, como la protección, el abrigo, el pudor y la decoración. En el caso de las personas entrevistadas, más allá del uso del vestido como protec- ción, ellas buscan expresarse de manera libre, incluso emitir un mensaje sobre su identidad con la intención de generar debate.

Malcolm Barnard menciona que, para la primera escuela del estudio de la comunicación -la escuela del «proceso»-, para poder entender la moda y el vestir como comunicación, no basta con comprenderla como un simple intercambio de mensajes. Es necesario entender el proceso de comunicación, que implica enviar un mensaje a través de un medio, lo que genera un efecto o reacción en aquel que recibe el mensaje. Para ello, es importante conocer la intención del emisor, la eficiencia del proceso de transmisión de dicho mensaje y su efecto en el receptor (Barnard, 2002). En este sentido, para expresar una declaración sobre la identidad propia a través de la ropa que se usa, las personas entrevistadas deben primero asegurarse de que este medio sea adecuado para que el mensaje se transmita correctamente. Ello, por ejemplo, implica usar un vestuario que no se contradiga con el discurso principal, que es la reivindicación de sus identidades.

Esto aplica también al momento de adjudicar roles de género de acuerdo con el vestuario que se utiliza. El «buen vestir», para nuestras personas entrevistadas, dicta el qué o el cómo vestir de acuerdo con el género de la persona asignado al nacer. Ellas coinciden en mencionar algunos casos en los que han recibido res- 
puestas violentas debido a su apariencia en ocasiones en que han usado prendas que transgreden lo que es esperado dentro de una comprensión binaria del género. Por ello, especialmente antes de acercarse a colectivos activistas, moderaban sus elecciones de ropa, a fin de mantenerse dentro del consenso de lo que es o no adecuado a sus cuerpos, sosteniéndose dentro del orden social.

Una idea compartida en las entrevistas hace mención a la rigidez, no solo de la oferta en la indumentaria, sino también en el estilo y las formas en que se utiliza la moda. Esta rigidez del vestir ocasiona que generalmente las personas limiten sus posibilidades de explorar estilos distintos por temor a la consecuente penalización de estos actos, por ejemplo, el rechazo de sus pares, o su aislamiento. Esto nos recuerda al concepto de dispositivo disciplinario de Foucault (2002), que, aplicado a la moda, nos permite entenderla como un sistema de control que rige sobre todos los miembros de la sociedad por igual, imponiendo sobre ella qué usar o qué no de acuerdo con la temporada pero también según el género, controlando o incluso censurando el discurso que se emite al vestir si este no sigue aquellas reglas establecidas.

En este sentido, el vestido puede cumplir también un rol contestatario, al hacer las veces de medio a través del cual puede emitirse un mensaje que genere nuevos ciones sociales. El utilizar trajes no concebidos para cierto tipo de cuerpos genera, en quienes los observan, una reacción y acaso una reflexión. Entonces, el vestir termina cumpliendo una función más: la de moldear o expandir ideas sobre cómo deben vestir -o no vestir- las personas de acuerdo con su género.

\subsection{Aspectos de estigma y discriminación asociados al vestir}

A pesar de que el indumento puede, en teoría, ser usado para abrir un diálogo, las personas entrevistadas reconocen que el uso de cierto tipo de prendas por cuerpos no hegemónicos puede ser una decisión que incrementa las posibilidades de sufrir actos discriminatorios. Estos actos limitan su libertad, hasta el punto de afectar su acceso a oportunidades básicas de subsistencia, como el trabajo o la educación. Como señala Butler al explicar el concepto de precariedad, «quienes no viven sus géneros de una manera inteligible entran en un alto riesgo de acoso y violencia» (2009, p. 323).

La libertad de tránsito en los espacios públicos es la afectación más común, en tanto que reciben miradas inquisitivas y sufren burlas, así como acoso sexual callejero. Las personas entrevistadas señalan que, al usar prendas que pronuncian su disidencia -mezclar elementos leídos como masculinos con otros decodificados como femeninos, por ejemplo-, sienten miedo de salir a la calle. «La sociedad 
tiende a ser violenta con cuerpos que visten ropas de otros géneros, sobre todo cuerpos masculinos vistiendo ropa femenina», declara Santiago.

Esta violencia no necesariamente implica que dejen de usar prendas de su preferencia, pues es parte de hacer visible su comunidad ante la sociedad y, especialmente, ante otras personas en proceso de autoexploración, que ahora pueden ver referentes de paz con su cuerpo e identidad en la calle.

Las personas entrevistadas también transitan espacios con códigos de vestimenta específicos para hombres y mujeres, tales como las oficinas de trabajo $u$ organizaciones públicas a las cuales deben asistir debido a su activismo. En estos entornos, existe el temor de no ser tomados/as en serio y, por ende, dudan al elegir ciertas prendas. Sin embargo, los temores, especialmente en las personas transgénero, pueden rápidamente escalar a la realidad, dado que para muchas personas trans parte del proceso de transición es adoptar una expresión de género distinta a la que han tenido previamente. Así, pueden perder su empleo o se les puede negar el ingreso a los espacios educativos a los que acostumbran asistir.

\section{Explica Gahela:}

La primera vez que yo pisé la universidad con ropa femenina o con ropa que esta sociedad atribuye a las mu- jeres, a mi profesora no le importó cuánto yo haya estudiado para exponer; ella era dueña del curso y no me podía dejar exponer.

Era la primera vez que le negaban exponer. Para Gahela decirle al mundo quién era ella a través de lo que llevaba puesto sobre la piel tenía como consecuencia que se le retiren los privilegios de los que en algún momento gozó. «Cosa que no sucedía antes, porque yo podía ser amanerada, pero seguía con una expresión de género que me ayudaba a conservar mis privilegios», añade.

Las recomendaciones reiteradas sobre qué tipo de ropa es más apropiada son otra forma de violencia que enfrentan las personas que habitan cuerpos disidentes. Estas sugerencias funcionan como estrategias de control y vienen de parte de su entorno cercano, así como desde personas completamente desconocidas, como vendedores/as en tiendas de ropa. En algunos casos, los comentarios empiezan desde una edad muy temprana, como narra Gahela: «A mí de chiquita me gustaba el huaynito. Agarraba las sábanas, las cortinas, y me agarraba como polleras. A nadie le gustaba, porque era como que... "tu hijito va ser maricón”». Asimismo, en espacios fuera de lo familiar, como en un centro comercial, personas desconocidas pueden hacer preguntas referidas a por qué compran en las secciones «femeninas» si no les corresponde vestirse así. 
Cuando Orlando empezó a usar prendas de colores más encendidos, su entorno le sugería usar ropa oscura para disimular la forma de su cuerpo. En sus palabras, «la gente dice: "no uses eso; te hace ver más gordito”. Yo les digo: “¿cuál es el problema? Lo soy"». Además de habitar un cuerpo gordo, Orlando es afrodescendiente y usar cierto tipo de prendas activa los imaginarios racistas de las personas a su alrededor. «La violencia social que existe por mucho tiempo ha condicionado mi forma de vestir», detalla Orlando. «Cuando voy a un lugar con ropa sport, siempre una persona de seguridad está detrás mío. Terminé tratando de acomodarme a usar ropa mucho más formal». Por un tiempo, la ropa formal cumplió la tarea de anticiparse a los prejuicios de su entorno o, en sus palabras, «compensar por los imaginarios racistas arraigados. Al ver una persona afroperuana, jamás asumirías que es una persona académica». En este caso, la discriminación no solo limitaba su expresión, sino su comodidad personal.

\section{Conclusiones}

Dado que este artículo tiene un fin exploratorio, no busca ser concluyente, sino dejar algunos apuntes para una reflexión sobre cómo las personas que habitan cuerpos no hegemónicos usan el indumento para expresar su género y visión del mundo, e iniciar procesos de comunicación.

Dicho lo anterior, las entrevistas sugieren 108 mentaria dirigida a los cuerpos no hegemónicos y que, a raíz de sus identidades, las experiencias de compra pueden ser incómodas e, incluso, oportunidades para la discriminación. Ello se ha visto remediado por las personas entrevistadas recurriendo a la modificación de prendas y su personalización, y a la exploración de mercados en el extranjero a través de la compra en línea.

Confirmamos que el estilo propio es parte de la expresividad de estas personas y no solo cumple un rol protector (Entwistle, 2000). Así, para las personas entrevistadas el indumento es un medio de comunicación e interacción sociocultural (Barnard, 2002) que sirve para expresar y reclamar su lugar en la sociedad. La configuración de su estilo responde a la intención consciente de expresar su disidencia frente a los códigos del correcto vestir dentro de ciertos espacios formales, irrumpiendo de esta manera en la sintaxis o sistema de reglas de la moda, cuya manifestación más pura podría llamarse «buen vestir». Otros usos de la vestimenta que mencionan las personas entrevistadas son hacer visibles en la esfera pública las identidades que atraviesan sus cuerpos, abrir un espacio de discusión con personas que desconocen sus vivencias, y ser referentes para personas que experimentan diferentes tipos de discriminación y no se atreven aún a expresar su identidad sin miedo.

Pudimos observar que existe una variación en las funciones prioritarias que 
cumplía el vestir en los tres casos de estudio. Antes de acercarse al activismo, el vestir era utilizado para gratificar su impulso de pudor y reprimir sus identidades. Hasta allí, podríamos decir que estas personas protegían su permanencia en un grupo social que se regía sobre la base de normas sobre lo «correcto»; de esta forma, a través de su vestir recatado, comunicaban que estaban de acuerdo con estas reglas. El activismo y la aproximación a la experiencia de vestimenta de otras personas con cuerpos no hegemónicos permitieron el intercambio de mensajes más allá de las barreras en que se encontraban inicialmente. Entonces, el vestir empieza a ser utilizado como actividad de placer, medio de comunicación de sus identidades y demandas, y disconformidad con normas sociales y códigos morales que intentan limitar o patologizar sus cuerpos.

El estudio realizado por Klepp y Risst (2016) sobre estrategias de personas con cuerpos no hegemónicos para vestirse «apropiadamente» concluye que algunas prácticas utilizadas son la autoaceptación del cuerpo como una deficiencia -«todos/as tenemos problemas»-, la compensación - dirigir la atención hacia otros lugares-o la ignorancia -minimizar la importancia de la apariencia-. Estos no son discursos que se encontraron en las narrativas de las personas entrevistadas para este artículo. Por el contrario, para las personas entrevistadas, el vestir sus cuerpos tal como son es una forma de expresar sus identidades con entusiasmo y sin temor.

No obstante, la recepción de sus prácticas de vestimenta en algunos espacios puede ser muy negativa. Zambrini (2015) narra que la transgresión en el espacio público de los códigos indumentarios ha sido histórica y socialmente sancionada. Esto se ilustra en que, en respuesta a su expresión de libertad, las personas entrevistadas reciben discriminación, rechazo o comentarios correctivos, o sus identidades terminan siendo cuestionadas. Como explican Butler (1990, 2002) y Murray (2007), los actos de género y disidencia corporal en contextos restrictivos son sancionados en las interacciones sociales. Estos actos de sanción ocurren en el seno familiar, en los momentos de contemplación de ropa en tiendas e, incluso, en los espacios de activismo en los que participan. Al ser menos "discretos» en la expresión de sus identidades usando la ropa, las personas con cuerpos no hegemónicos se llegan a enfrentar a la precariedad, con consecuencias tangibles como pérdida de empleo y negación de acceso a espacios educativos. De este modo, la vestimenta puede generar una amplificación de los problemas de discriminación que enfrentan en lo cotidiano.

Las personas entrevistadas aceptan que este conjunto de actitudes y comportamientos discriminatorios pueden hacerlas sentir inseguras, y, en este sentido, la vestimenta, que funciona como medio 
de comunicación, da pie a interacciones desagradables. Así, aceptan lo anterior, pero sostienen también que parte de su lucha activista consiste en generar incomodidad, pues esta significa un primer paso para suscitar preguntas y abrir el debate, lo cual, a su vez, puede llevar a la normalización de la existencia de otras identidades y otros cuerpos.

\section{Limitaciones}

Si bien, a través de las entrevistas a profundidad, se ha logrado identificar ciertas coincidencias en los usos y experiencias del vestir en los tres casos de estudio, estas no llegan a ser patrones, pues el número de personas entrevistadas es muy limitado aún para alcanzar saturación de datos.

En las conversaciones, se menciona que el activismo y el feminismo en particular tuvieron cierta influencia en el proceso de valoración positiva de sus identidades y su consiguiente expresión a través del medio del indumento; sin embargo, en futuros estudios valdría la pena confirmar esto y explicar por qué las experiencias de activismo logran ser así de relevantes, y profundizar sobre qué rol juega la comunicación entre pares dentro de este proceso.

Desde los estudios de género, se podría también abordar, en el futuro, qué estéticas disruptivas, patrones binarios y no bi- transitan entre ambos las personas que se autoidentifican como disidentes, a fin de profundizar en de qué manera actúan las normas sociales para perfilar lo «correcto» en nuestra sociedad. 


\section{REFERENCIAS}

Berger, P. y Luckmann, T. (1986). La construcción social de la realidad. Buenos Aires, Argentina: Amorrortu.

Barnard, M. (2002). Fashion as communication (2. ${ }^{\mathrm{a}}$ ed.). Londres, Reino Unido: Routledge.

Butler, J. (1988). Performative acts and gender constitution: An essay in phenomenology and feminist theory. Theatre Journal, 4O(4), 519-531.

Butler, J. (1990). Gender trouble: Feminism and the subversion of identity. Nueva York, Estados Unidos de América: Routledge.

Butler, J. (2002). Cuerpos que importan. Sobre los límites materiales y discursivos del «sexo» (Trad. A. Bixio). Buenos Aires, Argentina: Paidós.

Butler, J. (2009). Performatividad, precariedad y políticas sexuales. AIBR. Revista de Antropología Iberoamericana, 4(3), 321-336.

Cahill, S. E. (1989). Fashioning males and females: Appearance management and the social reproduction of gender. Symbolic Interaction, 12(2), 281-298. https://doi.org/10.1525/ si.1989.12.2.281

Calefato, P. (2002). El sentido del vestir. Valencia, España: Engloba.

Contrera, L. (31 de enero de 2017). Activismo gordo sudaca, latino, punk y desviado / Entrevistadora: Gabby de Cicco. Asociación para los Derechos de las Mujeres y el Desarrollo. Recuperado de https://www.awid.org/es/ noticias-y-an\%C $3 \%$ A1lisis/activismo-gordo-sudaca-latino-punk-y-desviado
Costa, F. (mayo, 2008). El dispositivo fitness en la modernidad biológica. Democracia estética, just-in-time, crímenes de fealdad y contagio. Jornadas de Cuerpo y Cultura de la UNLP, La Plata. Recuperado de http://www.memoria.fahce.unlp.edu.ar/trab_eventos/ ev.647/ev.647.pdf

Cruz de Amenábar, I. (1986). Trajes y moda en Chile 1650-1750: jerarquía social y acontecer histórico. Historia, (21), 177-214. Recuperado de http://revistahistoria.uc.cl/index.php/rhis/article/view/781/603

Eco, U. (1976). El hábito hace al monje. En F. Alberoni, G. Dorfles, U. Eco, M. Livolsi, G Lomasi y R. Sigurtà, Psicología del vestir (Trad. C. Manzano). Barcelona, España: Lumen.

Entwistle, J. (2000). The fashioned body: Fashion, dress and modern social theory. Cambridge, Reino Unido: Polity Press.

Entwistle, J. (2002). El cuerpo y la moda. Una visión sociológica (Trad. A. Sánchez). Barcelona, España: Paidós.

Entwistle, J. (2014). Fashion \& the fleshy body: On dress as an embodied practice. Vestoj. The Platform for Critical Thinking on Fashion. Recuperado de http://vestoj.com/fashion-and-thefleshy-body-on-dress-as-an-embodied-practice/

Flügel, J. C. (2015). Psicología del vestido (Trad. C. Gual). España: Melusina.

Foucault, M. (2002). Vigilar y castigar. Nacimiento de la prisión (Trad. A. Garzón). Buenos Aires, Argentina: Siglo Veintiuno. 
Klepp, I. G. y Rysst, M. (2016). Deviant bodies and suitable clothes. Fashion Theory, 21(1), 79-99. https://doi.org/10.1080/1362704X.2016.1138658

Kogan, L. (1993). Género-cuerpo-sexo: apuntes para una sociología del cuerpo. Debates en Sociología, (18), 35-57. Recuperado de http://revistas.pucp. edu.pe/index.php/debatesensociologia/article/view/6676

Lipovetsky, G. (1996). El imperio de lo efímero. La moda y su destino en las sociedades modernas. Barcelona, España: Anagrama.

Murray, S. (2007). Corporeal knowledges and deviant bodies: Perceiving the fat body. Social Semiotics, 17(3), 361-373. https://doi. org/10.1080/10350330701448694

Ostrov, A. (2015). Introducción. Cuerpos desviados. Orillas, (4). Recuperado de http://orillas.cab.unipd.it/orillas/articoli/numero_4/ooOstrov_rumbos. pdf

Real Academia Española y Asociación de Academias de la Lengua Española. (2014). Vestir. En Diccionario de la lengua española (23. ${ }^{\mathrm{a}}$ ed.). Recuperado de https://dle.rae.es/vestir?m=form

Rizo García, M. (2009). La comunicación, ¿ciencia u objeto de estudio? Apuntes para el debate. Question, 1(23). Recuperado de https://perio.unlp. edu.ar/ojs/index.php/question/article/view/887

Rudd, N. A. y Lennon, S. J. (2000). Body image and appearance-management behaviors in college women. Clothing and Textiles Research Journal, 18(3), 152-162. https://doi. org/10.1177/0887302X0001800304
Saltzman, A. (2004). El cuerpo diseñado. Sobre la forma en el proyecto de la vestimenta. Buenos Aires, Argentina: Paidós.

Tarrant, S. y Jolles, M. (Eds.). (2012). Fashion talks: Undressing the power of style. Albany, Estados Unidos de América: State University of New York Press.

Twigg, J. (2009). Clothing, identity and the embodiment of age. En J. Powell y T. Gilbert (Eds.), Aging and identity: A postmodern dialogue. Nueva York, Estados Unidos de América: Nova Science Publishers.

Zambrini, L. (2015). Género, vestido y espacio público. Revista Inclusiones, 2(Núm. Esp.), 39-54. Recuperado de https:// www.academia.edu/17280603/Género_vestido_y_espacio_público 